\title{
Design, testing and validation of an innovative web-based instrument to evaluate school meal quality
}

\author{
Emma Patterson* , Anna-Karin Quetel, Karin Lilja, Marit Simma, Linnea Olsson and \\ Liselotte Schäfer Elinder \\ Department of Public Health Sciences, Division of Social Medicine, Karolinska Institutet, Norrbacka, level 3 , \\ 17176 Stockholm, Sweden
}

Submitted 9 March 2012: Final revision received 13 June 2012: Accepted 1 August 2012: First published online 25 September 2012

\begin{abstract}
Objective: To develop a feasible, valid, reliable web-based instrument to objectively evaluate school meal quality in Swedish primary schools.

Design: The construct 'school meal quality' was operationalized by an expert panel into six domains, one of which was nutritional quality. An instrument was drafted and pilot-tested. Face validity was evaluated by the panel. Feasibility was established via a large national study. Food-based criteria to predict the nutritional adequacy of school meals in terms of fat quality, iron, vitamin D and fibre content were developed. Predictive validity was evaluated by comparing the nutritional adequacy of school menus based on these criteria with the results from a nutritional analysis. Inter-rater reliability was also assessed.

Setting: The instrument was developed between 2010 and 2012. It is designed for use in all primary schools by school catering and/or management representatives. Subjects: A pilot-test of eighty schools in Stockholm (autumn 2010) and a further test of feasibility in 191 schools nationally (spring 2011).

Results: The four nutrient-specific food-based criteria predicted nutritional adequacy with sensitivity ranging from 0.85 to $1 \cdot 0$, specificity from 0.45 to $1 \cdot 0$ and accuracy from 0.67 to $1 \cdot 0$. The sample in the national study was statistically representative and the majority of users rated the questionnaire positively, suggesting the instrument is feasible. The inter-rater reliability was fair to almost perfect for continuous variables and agreement was $\geq 67 \%$ for categorical variables.

Conclusions: An innovative web-based system to comprehensively monitor school meal quality across several domains, with validated questions in the nutritional domain, is available in Sweden for the first time.
\end{abstract}

School meal provision has a long history in Sweden, dating from the 19th century. A free warm lunch for all pupils in compulsory school has been enshrined since 1997 in the Education $\mathrm{Act}^{(1)}$. School meals in other countries have been shown to contribute significantly to overall healthy dietary habits ${ }^{(2)}$, yet monitoring of school meal quality in Sweden has historically not received much attention. National guidelines exist for school food, as do national nutritional guidelines ${ }^{(3)}$, but are not compulsory. The legislation has recently been revised and from July 2011 explicitly states that school meals must also be 'nutritious', i.e. fulfil Swedish nutritional recommendations ${ }^{(4)}$.

Exactly how this new requirement will be interpreted or enforced by national authorities remains to be seen at the time of writing (June 2012). Other countries with large-scale school meal programmes often issue nutrient-based standards or food-based standards, or both $^{(5,6)}$. Nutrient-based standards require nutritional analysis software coupled to an accurate database, plus the competence to use it and interpret the results. A recent survey in Sweden suggested that one in five municipalities has no catering manager and that only $40 \%$ currently nutritionally analyse their school food menus ${ }^{(7)}$. The US Department of Agriculture, responsible for the US National School Lunch Program, has recently eschewed its 'nutrient standard menu planning' approach in favour of its 'food-based menu planning',(8), citing simplicity and easier communication of the standards among its reasons.

In early 2010, in anticipation of this new legislation, we began developing an instrument that could objectively and simply evaluate school meal quality, at school level. School meal quality is a broad construct consisting 
of several domains, just one of which is nutritional adequacy. The present paper describes the processes involved, which aimed to:

1. Operationalize the construct 'school meal quality' and develop a feasible, valid and reliable instrument appropriate for use by all Swedish primary schools.

2. Develop and evaluate the predictive criterion validity of relevant nutrient-specific food-based criteria that can assess the nutritional adequacy of a school's food provision.

\section{Methods}

\section{Operationalization of the construct 'school meal quality'}

The purpose was to identify all critical areas/domains that should be included in an instrument that aims to measure the complex construct 'school meal quality'. In spring 2010, key persons and stakeholders in the area of school food were identified, some using the 'snowball method' where contacted persons nominated other persons in turn (Table 1). We identified three main themes in advance that the instrument should cover (Fig. 1a), based on previous work done on this area ${ }^{(9,10)}$, and held a series

Table 1 Semi-governmental bodies and organizations represented in the expert panel

Local authority catering managers

School principals

School catering managers

The National Food Agency

The National Institute of Public Health

The Swedish Association of Local Authorities and Regions

NCFF - The Swedish National Centre for Child Health Promotion

The Swedish Environmental Management Council

Researchers and non-governmental organizations working with school food of consultations on these themes with relevant experts. Brainstorming techniques led to a list of six domains, namely: (i) food and meal availability (e.g. meal choice/ assortment); (ii) nutritional adequacy (i.e. type of foods provided); (iii) safe food (i.e. hygienic food, provision for special diets); (iv) service and pedagogy (e.g. the meal environment, integration of meal/mealtimes into the school day); (v) environmental impact (e.g. monitoring of waste, transport, organic foods); and (vi) organization and policy (e.g. staff education, policies).

\section{Design of the instrument}

Questions in all six domains were drafted and sent to the experts for written comment and subsequently revised where necessary. Care was taken to formulate the questions as clearly and unambiguously as possible. The questionnaire was tailored, meaning sections were hidden where not relevant (i.e. no further questions asked about breakfast quality if breakfast not served). Questions primarily took the form of 'select' questions where the answer is selected from a (visible) list. Explanatory text was provided for many questions, but this was carefully worded so as not to influence the respondent's choice. Potential answers were carefully chosen to cover every possibility, including sometimes 'not relevant'. Every question had a 'don't know' option so that a respondent would not be forced to pick an incorrect answer in order to progress. All questions within a level were obligatory as this eased tailoring of the questionnaire, coding of the answers and generation of the automatic feedback. Open-ended questions were avoided for the opposite reason and to reduce respondent burden. For the pilot study, questions were assigned to two levels: Level 1 contained obligatory questions in all six domains and Level 2 contained optional questions in most domains. Feedback from the pilot study was generally positive but persistent concerns about the high respondent burden (a)

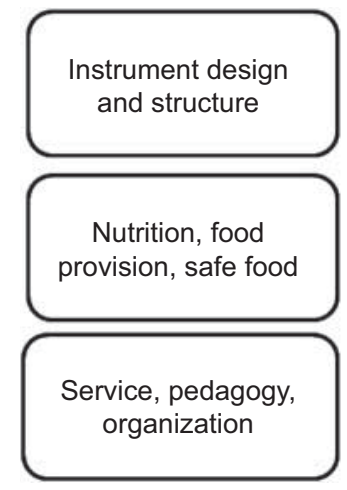

(b)

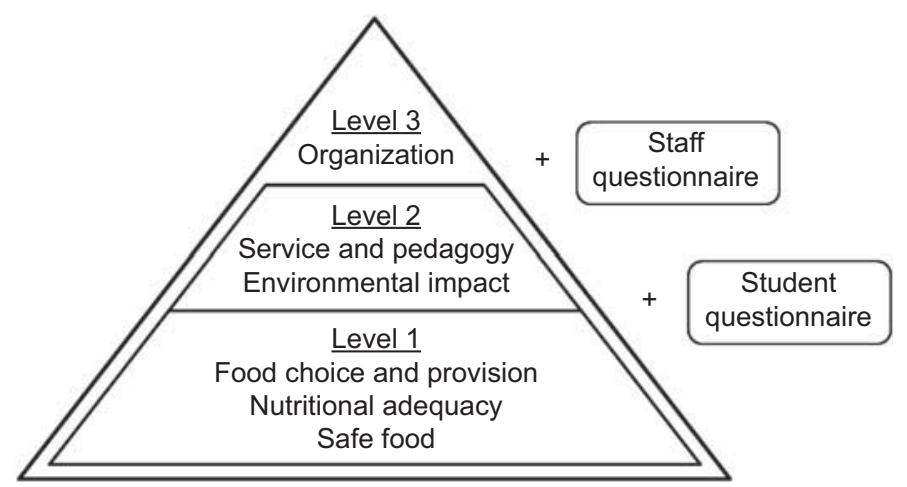

Fig. 1 The instrument and its domains: (a) the themes of the initial three expert panel consultations; (b) the final version of the instrument and all included domains. The shape illustrates the order and indicates the relative size of each level and the expected time required for completion. Within each level, all questions are compulsory, but Levels 2 and 3 are optional. Questionnaires for students and staff to provide their subjective opinions about the school meal quality are also available to the schools 
prompted us to reduce Level 2 and create a Level 3, both optional (Fig. 1b). An important feature was added to the final version, after all tests and validation studies: as soon as Level 1 is completed, users can download a detailed report for the school that shows the school's answers and through the use of user-friendly colourcoding highlights areas that the school excels at and those that the school should improve.

\section{Development of food-based criteria}

Criteria were developed for specific nutrients that allow the instrument to judge if a school's food provision is

Table 2 The four nutrient-specific food-based criteria

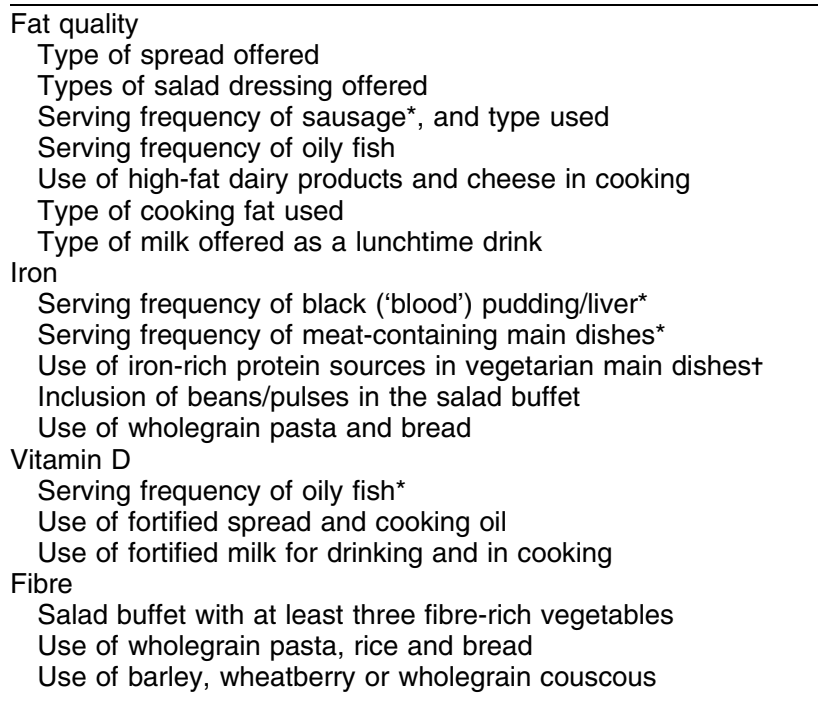

*The criterion is weighted in the calculation of the overall score for each nutrient.

tConsidered a criterion only if a vegetarian main dish is served more often than once weekly. likely to fulfil/is likely to almost fulfil/is unlikely to fulfil the Swedish Nutrition Recommendations (SNR), based on the school's responses to certain food-related questions. Relevant nutrients of concern in the prevailing diets of Swedish school-aged children were identified based on reviews of both published literature (e.g. reports from small-scale studies on food habits ${ }^{(11)}$ ) and grey literature, including national non-binding guidelines for school food $^{(3)}$, national nutritional recommendations ${ }^{(12)}$ and the most recent national survey of food habits in children ${ }^{(13)}$, namely: high intakes of saturated fat and sugar, and low intakes of polyunsaturated fats, iron, vitamin D and fibre. Questions based on significant and/or rich sources of these nutrients in the Swedish diet were developed which make up four food-based criteria (FBC), one for each nutrient (Table 2). The answers to each of these questions resulted in a score of 0,1 or 2 , which were then summed and used to give an overall score for each nutrient. Certain questions were weighted. A detailed description of the calculation of the criteria can be provided on request.

\section{Pilot study}

The purpose of the pilot study was to test the instrument on a small scale and identify gross inconsistencies in the data gathered. In autumn 2010, principals and catering managers in all 141 municipally run primary schools in Stockholm city (Fig. 2) were contacted by both email and regular mail and invited to participate. School catering managers were also informed about the study by the municipal catering manager at a meeting. In order to assess the concurrent validity of the school's answers to questions provided by the school in the online instrument concerning nutritional adequacy and selected other parameters, an on-site observation was performed using a printed version of the questions ${ }^{(14)}$. Before the study

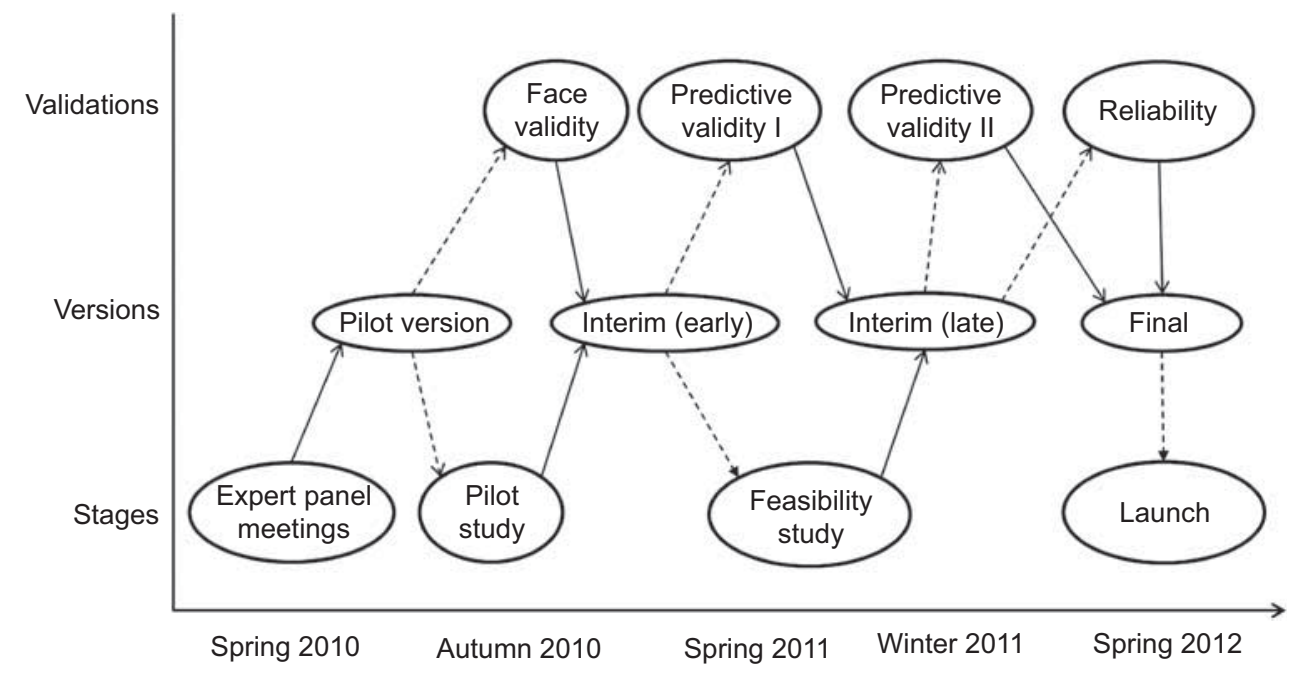

Fig. 2 Timeline showing the stages of development of the instrument $(\longrightarrow=$ led to the development of/changes to; - - - $->=$ was used in) 
began, a random selection was made of fifteen schools to be visited after completion of the questionnaire, covering all kitchen types - those that produce all food on-site, those that receive the main warm dish from another kitchen, those that serve $>500$ portions and $<500$ portions. A proportionate number of schools of each type were chosen at random. A further fifteen replacement schools were similarly chosen. If a selected school completed the questionnaire, the school could be visited; if it did not, a replacement school that completed the questionnaire was chosen. Schools were verbally informed that they may be chosen for a visit, but were not informed of their selection until the morning of the intended visit, when the school catering manager was contacted by telephone and asked if they would consent to the visit. The purpose of the short notice period was to reduce the risk of influencing the observation. One observer (M.S.) visited the kitchen and serving area and recorded observations for comparison against the answers provided by the school. The observer also recorded any problems/opinions the school had about the instrument. Agreement between the observer's observations and the school's answers was used to judge the concurrent validity of the school's responses.

\section{Estimation of face validity}

Based on user feedback from the pilot study certain questions were reformulated. These questions were sent to the expert panel for a systematic assessment of face validity. Experts were asked to rate each question from 1 (not important) to 4 (very important). A final meeting was held to discuss the content with the panel in February 2011.

\section{Feasibility study}

The aim was to gather baseline data prior to the introduction of the new nutritional requirements for school lunches and to establish the feasibility of the instrument on a larger scale. Data were collected from March to June 2011 (Fig. 2). A nationally representative random sample of $10 \%$ ( $n$ 429) of all schools with at least twentynine enrolled pupils was made using the Swedish National Agency for Education's registry. For each school nine replacement schools were also identified. Schools were sent an invitation letter, informing of the purpose of the study, that participation was voluntary and how their data would be handled. Schools were also contacted via email, and reminder emails and a postcard were sent. If a school declined to participate, or did not contact us after a certain length of time, the first replacement school was contacted and if necessary a subsequent replacement school was contacted for as long as the study continued. The schools were invited to complete as many levels of the instrument as they wished. In order to be considered a participant, completion of at least Level 1 was required. At the end of each level were a number of evaluation questions. Rate of participation, representativeness of the study sample and user satisfaction with the instrument were used to indicate feasibility.

\section{Predictive criterion validation I}

We validated the ability of the nutrient-specific FBC to assess nutritional quality using the results of a nutritional analysis of school menus as the reference standard. We used pre-existing menus which had already been entered into a commercial menu-planning programme. School menus were selected by a contact person at the planning service, de-identified and made accessible to us. The menus were to be chosen for their level of detail and completeness and not on nutritional quality. Of the twenty provided, one was on closer inspection found to be insufficiently detailed and was subsequently excluded. In order to increase the variability of the menus ( $n$ 19), they were duplicated and the accompaniments (salad, bread and spread) were standardized such that any actual accompaniments were replaced with two standards: one optimal (good salad, high-fibre bread, low-fat spread) and one suboptimal (poor salad, low-fibre bread, high-fat spread).

A lunch should provide $30 \%$ of energy and nutrients according to the $\mathrm{SNR}^{(12)}$ and less than $10 \%$ of energy from saturated fat. Each new menu ( $n$ 38) was classified according to the results of the nutritional analysis as meeting the SNR, almost meeting the SNR and not meeting the SNR (see Table 3). Based on the information in the menus, the questionnaire was then completed by one researcher (K.L.) and schools were classified according to the FBC as likely fulfilling/possibly fulfilling and unlikely to fulfil recommendations for each nutrient. The predictive validity of the $\mathrm{FBC}$, i.e. the ability of the criteria to correctly predict the nutritional adequacy, was analysed.

Table 3 Nutrition recommendations for lunch and the corresponding requirements (in parentheses) for children in the age range 10-13 years

\begin{tabular}{|c|c|c|c|c|c|c|}
\hline & \multicolumn{2}{|c|}{ SNR met } & \multicolumn{2}{|c|}{ SNR almost met } & \multicolumn{2}{|c|}{ SNR not met } \\
\hline Saturated fat & $\leq 10 \%$ & ergy & $10 \cdot 1-11 \%$ & nergy & $>11 \%$ & ergy \\
\hline Iron & $\geq 30 \%$ of $\mathrm{RDI}$ & $(\geq 3 \cdot 3 \mathrm{mg})$ & $25-29 \cdot 9 \%$ of $\mathrm{RDI}$ & $(2 \cdot 8-3 \cdot 2 \mathrm{mg})$ & $<25 \%$ of $\mathrm{RDI}$ & $(<2.8 \mathrm{mg})$ \\
\hline Vitamin D & $\geq 30 \%$ of RDI & $(\geq 2 \cdot 3 \mu \mathrm{g})$ & $25-29 \cdot 9 \%$ of RDI & $(1 \cdot 9-2 \cdot 2 \mu \mathrm{g})$ & $<25 \%$ of $\mathrm{RDI}$ & $(<1.9 \mu \mathrm{g})$ \\
\hline Fibre $^{*}$ & $\geq 30 \%$ of RDI & $(\geq 7 \cdot 4 \mathrm{~g})$ & $25-29 \cdot 9 \%$ of RDI & $(6 \cdot 1-7 \cdot 3 \mathrm{~g})$ & $<25 \%$ of RDI & $(<6 \cdot 1 \mathrm{~g})$ \\
\hline
\end{tabular}

SNR, Swedish Nutrition Recommendations; RDI, Recommended Daily Intake.

The categories of 'SNR almost met' and 'SNR not met' were defined by us for the purpose of the validation.

*Based on recommendations for adults of $2 \cdot 5 \mathrm{~g} / \mathrm{MJ}$. 


\section{Predictive criterion validation II}

The second validation was similar to the first with the following amendments: the nutritional analysis was based on information gathered in person from schools, rather than pre-entered menus and standardized accompaniments; the nutrient-specific FBC had been revised according to the results of the first validation study; and some questions had been revised slightly. Schools were visited by one observer (L.O.) to collect menus from a convenience sample of two municipalities without centrally administered menus or municipal catering managers. The school catering managers were contacted by letter and telephone in alphabetical order of the schools until at least six in each municipality had agreed to participate. During the visit, recipes for 4 weeks plus other relevant information about school food provision (i.e. type of milk, bread, salad buffet, etc. typically offered) were gathered. The schools were instructed to complete the questionnaire basing their answers on those 4 weeks, and to do so within 2 weeks of the visit. The observer (L.O.) also completed the questionnaire based on the information gathered at the school, approximately 1 month after menu collection. For the validation study these answers were used as the reference, to eliminate potential user error. To increase the sample size, twelve new menus were created by pairing the original menus at random twice and calculating the mean of these new pairs. As in the previous validation, the menus ( $n$ 24) were nutritionally analysed and classified according to the SNR, and from the questionnaire answers the schools were classified using the FBC. As before, the predictive validity of the FBC for each nutrient was evaluated.

\section{Reliability}

As this instrument is designed to be used repeatedly by schools, we tested the inter-rater reliability of the instrument, comparing the school's results with those of the observer from criterion validation study II.

\section{Statistical analysis}

Descriptive statistics were used to analyse the results of the face validation study, pilot study and feasibility study. The representativeness of the sample in the feasibility study was assessed by $\chi^{2}$ tests. The results of predictive criterion validation study I and II were analysed using measures of specificity, sensitivity, positive predictive value and the likelihood ratio where possible. Cohen's weighted $\kappa$ (interpreted according to Altman's scale ${ }^{(15)}$ ) was also calculated to evaluate agreement between nutritional adequacy as determined by the FBC and the results of the nutritional analysis. Inter-rater reliability was assessed using inter-class correlation for continuous variables and percentage agreement for categorical variables. Statistical analysis was performed using the statistical software package IBM SPSS Statistics version 20. Nutrition analysis was performed using Mashie (Mashie AB,
Sweden). All random selections were carried out by assigning random numbers generated by SPSS to units and then choosing units in ascending order.

\section{Results}

\section{Pilot study}

Of the 141 schools in Stockholm city, eighty-six participated. All schools that completed the questionnaire and that were eligible to receive a visit consented to the visit. Schools were visited a mean of $10 \mathrm{~d}$ (SD $7 \mathrm{~d}$, range 2-22d) after they had completed the questionnaire. For a number of questions the concurrent validity between the school's answers and the observer's was poor (data not shown). In subsequent versions of the instrument these questions were either revised (by rephrasing the question, clarifying the accompanying explanatory text, or altering the layout of the question to make it more user-friendly) or else removed.

\section{Face validity}

In total, eleven experts rated the face validity of the instrument after revisions arising from the pilot study. The mean score for all 110 questions was 3.6 out of 4 . Only six questions had a score of less than $3 \cdot 0$. Of these, four no longer appear in the final version, one was revised and one (on number of portions served) is not included in any FBC and was kept, unchanged.

\section{Feasibility study}

In total, 695 schools were contacted (429 original and 266 replacement schools). The response rate (i.e. those that completed Level 1) was $27 \%$ ( $n$ 191). Of those schools that completed Level 1, 64\% ( $n$ 122) went on voluntarily to complete Level 2 and of those 97\% ( $n$ 118) continued to Level 3. Responses to the evaluation questions indicated that $73 \%, 89 \%$ and $94 \%$ of schools thought that Levels 1, 2 and 3, respectively, were 'relatively easy' or 'very easy' to answer. The median (self-reported) time required was $60 \mathrm{~min}$ for Level 1, $15 \mathrm{~min}$ for Level 2 and 10 min for Level 3.

Participating schools were statistically representative of the source population (i.e. all schools with twenty-nine or more pupils) in terms of geographical spread (i.e. three main geographical regions), school organizational form (municipality-run or privately run) and school size (29-100 pupils, 101-300 pupils or 301+ pupils).

\section{Predictive criterion validation I}

Of the four FBC, three had at least 'good' agreement with the results from the nutritional analysis (Cohen's weighted $\kappa>0 \cdot 60$, data not shown). Specificity and sensitivity were both above $70 \%$ with the exception of sensitivity of the FBC for iron, which also had the lowest $\kappa$ value (data not shown). Based on these results, the FBC were revised in preparation for the second validation. 
Table 4 Criterion validity of the nutrient-specific FBC compared with results of a nutritional analysis

\begin{tabular}{|c|c|c|c|c|c|c|c|}
\hline & & & Sensitivity & Specificity & PPV & Accuracy & Likelihood ratio+* \\
\hline Vitamin D & \multicolumn{2}{|c|}{ SNR } & & & & & \\
\hline FBC & Met & Not met & & & & & \\
\hline $\begin{array}{l}\text { Satisfactory } \\
\text { Unsatisfactory }\end{array}$ & $\begin{array}{l}0 \\
0\end{array}$ & $\begin{array}{r}0 \\
24\end{array}$ & NA & $1 \cdot 0$ & NA & $1 \cdot 0$ & NA \\
\hline Fibre & \multicolumn{2}{|c|}{ SNR } & & & & & \\
\hline FBC & Met & Not met & & & & & \\
\hline Satisfactory & 23 & 0 & 0.96 & NA & $1 \cdot 0$ & 0.96 & NA \\
\hline $\begin{array}{l}\text { Unsatisfactory } \\
\text { Fat quality } t\end{array}$ & \multicolumn{2}{|c|}{ SNR } & & & & & \\
\hline FBC & Met & Not met & & & & & \\
\hline Satisfactory & 2 & 0 & $1 \cdot 00$ & $1 \cdot 0$ & $1 \cdot 0$ & $1 \cdot 0$ & NA \\
\hline $\begin{array}{l}\text { Unsatisfactory } \\
\text { Iron }\end{array}$ & \multicolumn{2}{|c|}{ SNR } & & & & & \\
\hline FBC & Met & Not met & & & & & \\
\hline Satisfactory & 11 & 6 & $0 \cdot 85$ & $0 \cdot 45$ & 0.65 & $0 \cdot 67$ & $1 \cdot 55$ \\
\hline Unsatisfactory & 2 & 5 & & & & & \\
\hline
\end{tabular}

FBC, food-based criteria; SNR, Swedish Nutritional Recommendations; PPV, positive predictive value; NA, not applicable (indicates that the value cannot be calculated because of cells with zero counts).

*Positive likelihood ratio.

+Validated against SNR for saturated fat.

\section{Predictive criterion validation II}

The predictive validity of the revised nutrient-specific FBC is shown in Table 4 . Results are presented as twoway tables for meeting/not meeting SNR and a rating of satisfactory (i.e. likely to fulfil SNR)/unsatisfactory (i.e. likely to almost fulfil/unlikely to fulfil SNR) according to the FBC.

\section{Reliability}

For continuous variables which contributed to an FBC, the inter-class correlation ranged from 0.33 to 0.99 (fair to almost perfect agreement; Table 5). For categorical variables the raters assessed all of the components consistently in between eight and twelve (out of twelve) cases.

\section{Discussion}

We have developed a comprehensive web-based system to enable schools to evaluate their meal quality with a relatively simple, user-friendly instrument. The construct 'school meal quality' was operationalized into six domains: (i) food and meal availability; (ii) nutritional adequacy; (iii) safe food; (iv) service and pedagogy; (v) environmental aspects; and (vi) organization and policy. To the best of our knowledge this system is thus unique in terms of scope. The instrument has been evaluated for feasibility, face and criterion validity, and reliability. Valid nutrient-specific FBC have been developed that can predict the nutritional adequacy of a school's food provision.
The pilot study was designed to test the instrument on a small scale and to identify gross inconsistencies. That the visit of the observer took place in some cases a few weeks after the school used the instrument is unlikely to have affected the outcome as the school received no feedback about what changes to make and no advance warning about whether it was chosen for a visit. The feasibility study had a relatively low response rate. Contact with schools occurred only via mail/email and no personal contact was made, which is likely to have affected the likelihood of participation negatively ${ }^{(16)}$. In addition, no registry of school or municipality catering managers exists, making it difficult to contact these target groups directly. However, the final sample was still representative. The design of the instrument is intended to reduce perceived respondent burden and the positive user evaluation indicates that the instrument is indeed feasible. That the instrument is entirely web-based means that, due to the high penetration of Internet access in Sweden, it should be accessible in every school. It also makes possible one of the key features for users of the system - automatic tailored feedback that illustrates clearly the school's responses. The instrument is tailored, making it appropriate for every school's situation (by concealing questions irrelevant for a given school). Questionnaires for pupils and staff are also available as optional components, which have great potential for linkage of individual- and school-level data in the future.

The FBC can be thought of as screening tests for identifying schools with nutritionally adequate school meals. As with all such tests, some misclassification (i.e. false positives 


\begin{tabular}{|c|c|c|c|c|}
\hline & \multirow[b]{2}{*}{ ICC } & \multirow[b]{2}{*}{$95 \% \mathrm{Cl}$} & \multicolumn{2}{|c|}{ Agreement } \\
\hline & & & $n$ & $\%$ \\
\hline Fat quality FBC & & & 8 & 0.67 \\
\hline Type of spread offered & & & 11 & 0.92 \\
\hline Types of salad dressing offered & & & 8 & 0.67 \\
\hline Serving frequency of sausage & $0 \cdot 75$ & $0.34,0.92$ & & \\
\hline Type of sausage used & & & 8 & 0.67 \\
\hline Serving frequency of oily fish & $0 \cdot 61$ & $0 \cdot 11,0 \cdot 87$ & & \\
\hline Use of high-fat dairy products in cooking & $0 \cdot 60$ & $0 \cdot 58,0 \cdot 86$ & & \\
\hline Use of high-fat cheese in cooking & $0 \cdot 33$ & $-0 \cdot 18,0.73$ & & \\
\hline Type of cooking fat used & & & 11 & 0.92 \\
\hline Type of milk offered as a lunch-time drink & & & 10 & 0.83 \\
\hline Iron FBC & & & 10 & $0 \cdot 83$ \\
\hline Serving frequency of black ('blood') pudding/liver & $0 \cdot 88$ & $0.66,0.97$ & & \\
\hline Serving frequency of meat-containing main dishes & $0 \cdot 91$ & $0.69,0.97$ & & \\
\hline Use of iron-rich protein sources in vegetarian main dishes & $0 \cdot 79$ & $0.44,0.93$ & & \\
\hline Inclusion of beans/pulses in the salad buffet & & & 9 & $0 \cdot 75$ \\
\hline Use of wholegrain pasta & & & 11 & 0.92 \\
\hline Use of wholegrain bread & & & 12 & $1 \cdot 00$ \\
\hline Vitamin D FBC & & & 8 & 0.67 \\
\hline Serving frequency of oily fish & & $(\text { as before })^{\star}$ & & \\
\hline Use of cooking oil & & & 9 & 0.75 \\
\hline Use of fortified spread & & & 8 & 0.67 \\
\hline Use of fortified milk for drinking & & & 10 & 0.83 \\
\hline Use of fortified milk in cooking & & & 8 & 0.67 \\
\hline Fibre FBC & & & 11 & 0.92 \\
\hline Salad buffet with at least three fibre-rich vegetables & & & 11 & 0.92 \\
\hline Use of wholegrain pasta & & & 8 & 0.67 \\
\hline Use of wholegrain rice & & & 9 & $0 \cdot 75$ \\
\hline Use of wholegrain bread & & & & \\
\hline Use of barley, wheatberry or wholegrain couscous & & & 10 & 0.83 \\
\hline
\end{tabular}

FBC, food-based criteria; ICC, inter-class correlation (continuous variables). *The component is previously listed in the table.

and false negatives) is to be expected ${ }^{(17-19)}$. The criteria have been validated in two separate studies. The accuracy (schools correctly classified by the FBC) was very high for three FBC and somewhat lower for the fourth (iron), although the relatively small sample sizes mean that a further validation is warranted. We intend to validate these criteria again after the instrument has launched and a larger quantity of data is available. The FBC were originally developed based on a priori knowledge of dietary sources of these nutrients. Although this is a common method for the development of dietary scores and indices ${ }^{(20,21)}$, a complementary approach is the a posteriori method ${ }^{(22)}$. With 'real-world' data we may be able to develop datadriven criteria whereby schools that have nutritious school food are first identified and their menus are then analysed for the food choices/patterns that characterize them.

We attempted to validate a more nuanced grading of nutritional quality (SNR fulfilled/almost fulfilled/not fulfilled) in criterion validation II, but due to the low variability in the menus a large number of cells had zero counts which made this unfeasible. Both sets of menus, from both studies, had very little variability in terms of vitamin D and saturated fat, as very few met the SNR, and in criterion validation study II all menus met the SNR for fibre. We cannot draw conclusions from criterion validation study I as we adjusted the main fibre sources for the study. This low variability is not necessarily a flaw in our study design, and may well just reflect the general quality of school menus. When more data are available we will be able to confirm this.

The inter-rater reliability showed fair to almost perfect results, particularly for the continuous variables. A $\kappa$ statistic for the categorical variables would have been desirable but the many cells with zero counts made this unfeasible. However, the measure of percentage agreement does indicate reasonable agreement. A reliability analysis will be repeated with a larger sample.

The instrument has a number of limitations. The FBC focus on just four nutrients. However, in the absence of official standards that identify exactly which nutrients must be taken into consideration when planning school meals, we chose these four which we deemed crucial based on known issues in prevailing dietary trends in children. A high intake of salt is also a concern, but it was not considered feasible for the instrument to be able to capture salt content as so much is consumed in processed foods. The instrument does not attempt to capture the provision of fruit and vegetables, which are important markers of a high-quality diet. This was deemed unfeasible as the school lunch is always a cooked meal, and vegetables are very often incorporated into dishes and are therefore likely to be difficult to report accurately. The instrument does however capture fruit and vegetable provision for breakfast and 
snacks. It should be noted that the standard against which the criteria have been validated - nutritional analysis - is, while an appropriate method, not without problems. One source of error is that data on processed foods are often incomplete for nutrients and minerals and even saturated fat, which can lead to under/overestimations of content ${ }^{(23)}$. This may partly explain why according to the nutritional analysis schools did not reach the iron recommendations, but according to our criteria they did.

This system serves several important purposes. It will: (i) allow us to describe school food provision at various administrative levels (school, municipality and national); (ii) enable monitoring of the implementation of the new law concerning school food; (iii) provide feedback to schools upon which to base efforts for improvement; and (iv) provide data for research on school meals and health outcomes. Information from other data registries such as those on child growth or academic performance, and on school and municipality characteristics, will allow research questions about the importance of school meals for public health to be addressed. This system can potentially be expanded to evaluate the food systems of other public sector institutions, such as hospitals or care facilities for the elderly.

This system could potentially be adapted with relative ease to other countries wishing to take a similar comprehensive approach to evaluating school meal quality. Monitoring systems in other countries with established school lunch programmes vary, and due to the often decentralized nature of school meals, a unified national monitoring system is uncommon. In England, for example, audits of school caterers are conducted by a municipality employee $^{(6)}$. In the USA, the US Department of Agriculture conducts surveys of school food provision and of food consumption at pupil level periodically ${ }^{(24)}$. Estonia and Finland are two other countries with universal school meal provision where large-scale studies are conducted but a national monitoring system is currently lacking, although the need has long been identified ${ }^{(2)}$.

The instrument can in future be expanded to reflect new standards and guidelines. This is a considerable strength of this system - it is flexible and can be updated as necessary. It also means that data can be processed and aggregated soon after collection, so that information on school food provision can be disseminated promptly. The instrument is available at www.skolmatsverige.se.

\section{Acknowledgements}

Source of funding: This project was funded by the Swedish Association of Local Authorities and Regions, the National Institute of Public Health, the Department of Agriculture and Stockholm County Council. Conflicts of interest: No author has any conflict of interest to declare. Authors' contribution: E.P. designed the instrument, performed statistical analyses and wrote the manuscript; K.L., M.S. and L.O. gathered data, performed nutritional analysis and statistical analyses; A.-K.Q. designed the instrument; L.S.E. designed the study and wrote the manuscript. All authors critically revised the manuscript and approved the final version. Acknowledgements: The authors thank the SkolmatSverige expert panel for their considerable input, Maria Ramsten for data collection during the feasibility study and all participating schools.

\section{References}

1. Sveriges riksdag (1997) Förskoleklass och andra skollagsfrågor (Preschools and Other School Issues). Rule: Bill 1997/98: 6.

2. Raulio S, Roos E \& Prattala R (2010) School and workplace meals promote healthy food habits. Public Health Nutr 13, 987-992.

3. Livsmedelsverket (2007) Bra mat $i$ skolan (Good Food in School). Uppsala: Livsmedelsverket.

4. Sveriges riksdag (2010) Den nya skollagen - för kunskap, valfribet och trygghet (The New School Law - for Knowledge, Choice and Security). Rule: Proposition 2009/10:165.

5. Statens näringsdelegation (2008) Rekommendation för skolbespisning (Recommendations for School Meals). Helsingfors: Statens näringsdelegation.

6. School Food Trust (2008) A Guide to Introducing the Government's Food-based and Nutrient-based Standards for School Lunches. London: School Food Trust; available at http://www.schoolfoodtrust.org.uk/download/documents/ pdf/sft_nutrition_guide.pdf

7. Skolmatens Vänner (2011) Skolmatens Vänners kartläggning av Sveriges kommuner gällande de måltider som idag serveras på landets grundskolor och förskolor. Del 1 (Skolmatens Vänners' Survey of Swedish Municipalities and the Meals Served in the Country's Primary and Pre-schools. Part 1). Lund: Skolmatens Vänner; available at http://www.skolmatensvanner.se/pdf/kostchefer_om_ skolmat_2011_del_1.pdf

8. US Department of Agriculture, Food and Nutrition Service (2012) Nutrition Standards in the National School Lunch and Breakfast Programs. Fed Reg 77, 4088-4167.

9. Lundmark B (2002) Kvalitet som utsaga och praktik kvalitetsaspekter med fokus på skolmåltiden i Sverige (Quality as a statement and a practice - aspects of quality with a focus on school meals in Sweden). Licenciate Thesis, Uppsala University.

10. Callmer E \& Friedl A (2004) Kvalitetsmärkning av skolluncher - en utvärdering av ett webbaserat verktyg (Assessment of School Lunch Quality - an Evaluation of a Web-based Instrument). Stockholm: Stockholms Läns Landsting.

11. Patterson E, Wärnberg J, Kearney J et al. (2010) Sources of saturated fat and sucrose in the diets of Swedish children and adolescents in the European Youth Heart Study: strategies for improving intakes. Public Health Nutr 13, 1955-1964.

12. Alexander J, Anderssen S, Aro A et al. (2004) Nordic Nutrition Recommendations 2004 - Integrating Nutrition and Physical Activity. Copenhagen: Nordic Council of Ministers.

13. Barbieri HE, Pearson M \& Becker W (2006) Riksmaten barn 2003. Livsmedels- och näringsintag bland barn $i$ Sverige (Food and Nutrition Intake Among Children in Sweden). Uppsala: Livsmedelsverket.

14. Oppenheim AN (1992) Questionnaire Design, Interviewing and Attitude Measurement. London: Pinter.

15. Altman DG (1991) Practical Statistics for Medical Research. London: Chapman \& Hall.

16. Galea S \& Tracy M (2007) Participation rates in epidemiologic studies. Ann Epidemiol 17, 643-653.

17. Altman D \& Bland M (1994) Statistics notes. Diagnostic tests 2: predictive values. BMJ 309, 102. 
18. Altman DG \& Bland JM (1994) Diagnostic tests. 1: Sensitivity and specificity. BMJ (Clin Res Ed) 308, 1552.

19. Grimes D \& Schulz K (2005) Refining clinical diagnosis with likelihood ratios. Lancet 365, 1500-1505.

20. Kant AK (1996) Indexes of overall diet quality: a review. J Am Diet Assoc 96, 785-791.

21. Arvaniti F \& Panagiotakos D (2008) Healthy indexes in public health practice and research: a review. Crit Rev Food Sci Nutr 48, 317-327.
22. Newby PK \& Tucker K (2004) Empirically derived eating patterns using factor or cluster analysis: a review. Nutr Rev 62, 177-203.

23. Harrison GG (2004) Fostering data quality in food composition databases: applications and implications for public health. J Food Compost Anal 17, 259-265.

24. Gordon AR, Crepinsek MK, Briefel RR et al. (2009) The third School Nutrition Dietary Assessment Study: summary and implications. J Am Diet Assoc 109, 2 Suppl., S129-S135. 